\title{
Biology Education \& Health Education: A School Garden as a Location of Learning \& Well-being
}

\author{
Carolin Retzlaff-Fürst
}

Department of Didactics Biology, University of Rostock, Germany

Copyright $\bigcirc 2016$ by authors, all rights reserved. Authors agree that this article remains permanently open access under the terms of the Creative Commons Attribution License 4.0 International License

\begin{abstract}
Children and adolescents spend a large part of their day at school. Physical and mental problems result from physical inactivity, sitting positions at work and "indoor lifestyle" (WHO 2004). Therefore, health education is a major topic in school. Biology classes (scholastic) can make an important contribution in this context. Health as a person's state is composed by physical, mental and social aspects (WHO 1946, Hurrelmann 2010). The presence of nature can have positive effects on all components of the (subjective) well-being of humans at all ages. The fact has already been well proved by science (Ulrich 1984; Health Council of the Netherlands 2004; Barton/Pretty 2010). In the scholastic context environment or gardens hold various functions as (special) places for the contact between humans and nature: They are areas for explorative learning, they provide manifold sources for interdisciplinary teaching, they are spots to generate skills and recovery and they are places for nutritional and environmental education (Blair 2009; Jäckel 2010). Generally, school gardens may take over a significant function in view of health education and wellness of children and adolescents. As a consequence, practical work and other activities in a school garden let the place become a point for physical agitation, relaxation and stress reduction. School garden classes and school garden practice in most of the cases are only held in the lower age groups of pupils (primary school). An analysis shall show that school gardens also could be employed for the health education in higher grades (11th and 12th grade). Representative a course of pre-study students (teacher students and / or prospective teachers) of the second semester were interviewed and tested in the educational garden of the University of Rostock about their subjective well-being. As a result, it was proved that garden activities have highly positive effects on self-esteem.
\end{abstract}

Keywords School Garden, Health Education, Environmental Education, Self-esteem

\section{Introduction}

"As health is not merely the absence of disease or infirmity but a positive state of complete physical, mental and social well-being (WHO 1986), a healthy [working] environment is one in which there is not only an absence of harmful conditions but an abundance of health-promoting ones" (Brun 2007). Therefore, school has to fulfil further functions beyond education in the classical sense. On the one hand school is responsible for a healthy environment and has to develop awareness for a healthy environment. On the other hand, school has to provide skills which are necessary for a healthy life. Teaching and learning in a school garden has the potential to consider both of these aspects.

In the school garden, fruits and vegetables are grown. Many children don't know any more what goes into healthy eating, and why it's so important. In addition to growing fruits and vegetables, school gardening also supports to learn many that is important about healthy plants and healthy nutrition. But this is only one aspect of health promotion in school garden. The fact that the experience of nature has positive effects on health and well-being of people at all ages has already been well proved by science (Ulrich 1984; Health Council of the Netherlands 2004; Barton/Pretty 2010).

Stress is a very common phenomenon of daily life. Not only adults are concerned, but also children and juveniles suffer from stress. Good mental health is not just the result of absent physical or psychic diseases. It compromises for instance a balance between individual contentedness and a good stress management. Stress is medically defined as an organism's total response to environmental demands or pressures. It results from interactions between persons and their environment. These interactions can have positive or negative effects on health. Investigations show that, for instance, stress undoubtedly can be reduced by nature-oriented environment (Kaplan 1995; Kaplan/Kaplan 1989). Accordingly, the designed semi-natural landscapes of gardens could be areas of relaxation and stress reduction. Specifically working in the school garden could be a suitable way to achieve this. The way school gardens apart from their classical functions (for example growing vegetables and the associated nutritional effect) also affect health education of pupils at all ages by outdoor activities or open space work, so far has not been systematically analysed. 


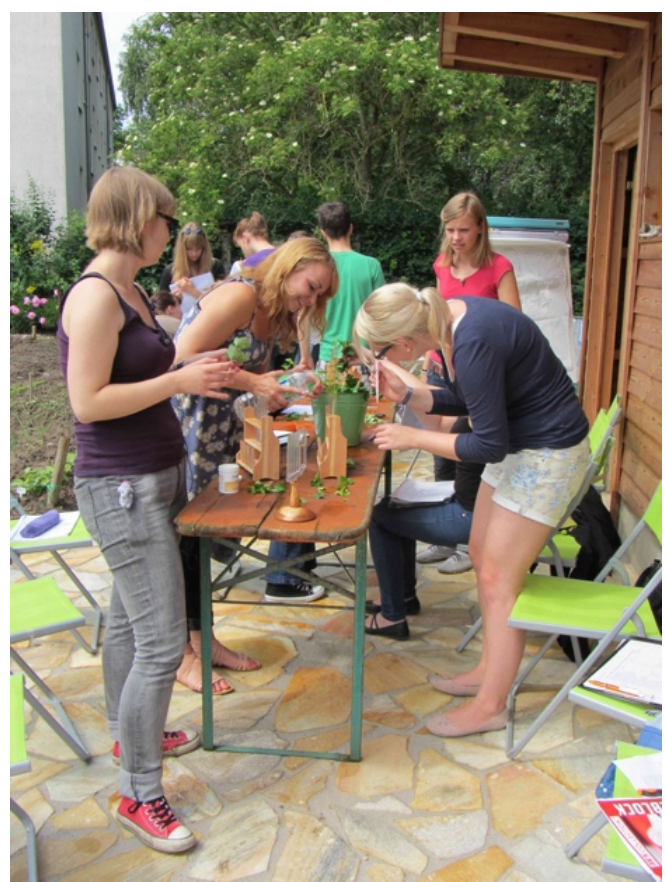

Figure 1. Educational garden, part of the didactics of biology, university of Rostock

Studies show, that, health, well-being and self-respect show a strong interaction (Ulrich 2010). Self-esteem is a short- and long-term determinant of mental health. It is commonly assessed in green-exercise research. "Self-esteem is an evaluation of a person's sense of worth or value, and there are strong positive correlations between self-esteem and health (Barton/Pretty 2010, p. 3947)".

Additionally, it is known that psychological stress harms the heart. Scientific studies show, exercise helps to lower blood pressure naturally (Zerzawy 1986).

The described interaction between health, general wellness and self-esteem leads to the question about the influence of gardening on the self-esteem of pupils and / or students:

Does practical garden work have an influence on

- the self-esteem and

- the blood pressure of students?

To assess the impact of green exercise on self-esteem we examined available data using standardized meta-analysis methods.

\section{Materials and Methods}

The quantitative examination is the pre-study for a prospective long-term study with pupils of secondary education levels.

Two groups of students were investigated: one group "self-esteem" and one group "blood pressure".

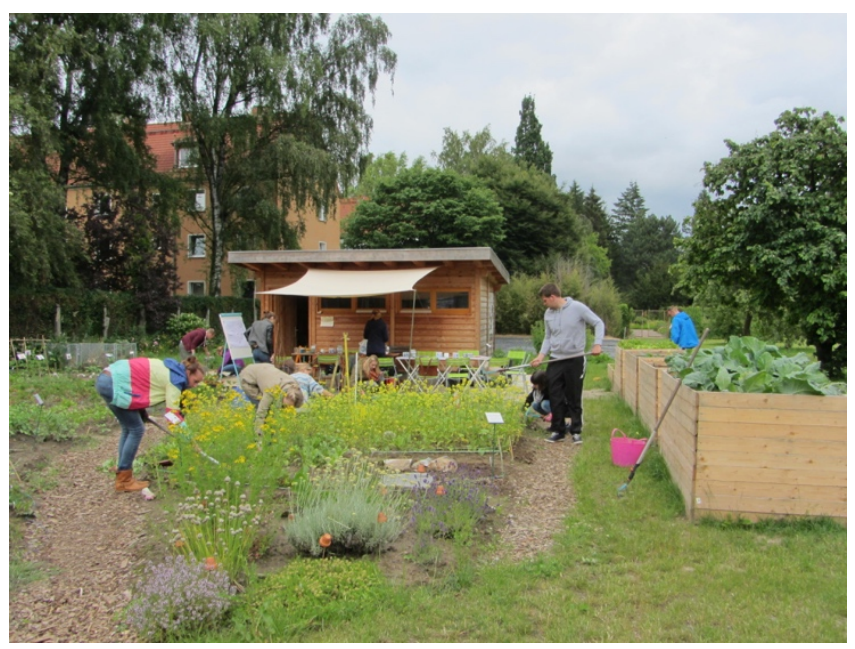

Figure 2. Students while hands-on experiments with plants from educational garden

The seminars took place in the educational garden, part of the didactics of biology, University of Rostock (Figure 1).

The seminars dealt with theoretical questions (45 min part 1) and scientific issues like experimentation and observation (approx. $90 \mathrm{~min}$ - part 2), for a time of 10 to 15 minutes the students did practical work in the garden patches (part 3). Two students are responsible for a piece in the garden (vegetable or flower patch). The plants (and also animals) are used for scientific issues as investigations or observations in part 1 and 2 of the seminar (Figure 2).

In the group "self-esteem" 38 students (teacher students) have been interviewed on four dates in June and July 2013. A total 14 seminars were held. The students answered the questionnaires before and after the seminar ( $\mathrm{t}=180 \mathrm{~min})$.

Groups A and B are students for teaching positions at grammar and middle schools. They participated in the investigation in one seminar, or, respectively, in two seminars. In group $\mathrm{C}$ are students for teaching positions at primary schools, they attended the study in four seminars.

As instrument of evaluation served the Rosenberg Self-Esteem Scale. The Rosenberg Self-Esteem Scale is a tool for assessing global self-esteem. The instrument is a part of self-esteem measure in social science research and is mainly used for adolescents. Ten statements are included in the self-report measure. Accordingly, the questionnaire shows the correlation between personality traits and self-esteem. It is a simple, unidimensional and economical use, providing reliable results of scale-measurement (Trautwein et al., 2006). It is a four-point scale ranging from "strongly agree" to "strongly disagree." The items were selected as a Guttman scale with 7 "contrived items." For the descriptive evaluation (averages, correlation, significant differences in pre-post-tests) all data have been compiled and illustrated in tables as well as graphics.

The quantitative study "blood pressure" took place in spring 2014. The study includes 10 teacher students for teaching positions at primary schools in 2 groups: group A "light gardening" and group B "heavy gardening". "Light 
gardening" means see to the seeds, the sowing, watering with a garden hose, weeding and harvesting. "Heavy gardening" means, that the students are are responsible for preparing the soil and the ,raised beds" for sowing, watering with a watering can and other heavy labour.

On the beginning of the investigation the students were trained to take their own blood pressure measurements. The stress-induced blood pressure was measured four times: 2 times at the beginning of the seminar, after gardening and at the end of the seminar. Measurements were controlled by an assistant and recorded in a data sheet. Blood pressure was measured with the sphygmomanometer SANITAS SBM03.

\subsection{Results Group "Self-esteem"}

The results show an increased value of self-esteem after practical garden work (Figure 3). The measurement of group A reflect a raised value of self-esteem.

For group A, the self-esteem increase from pre-value to post-value is not significant $(A=0,665 ; p \leq 0.05)$. The value enhancement in group $B$ is significant $(B=0,036 ; p \leq 0,05)$ and for group $\mathrm{C}$ it is even highly significant $(\mathrm{C}=0,010 ; \mathrm{p} \leq$ 0,01) (Table 1).

Table 1. comparison of value enhancement

\begin{tabular}{|c|c|c|c|}
\hline $\begin{array}{c}\text { Group/ } \\
\text { Self-esteem }\end{array}$ & Mean-difference & T-Value & $\begin{array}{c}\text { Significance } \\
(2 \text {-sided) }\end{array}$ \\
\hline A: Points- before/after & $-0,182$ & $-0,439$ & 0,665 \\
\hline B: Points- before/after & $-1,636$ & $-2,414$ & 0,036 \\
\hline C: Points- before/after & $-0,791$ & $-2,698$ & 0,010 \\
\hline
\end{tabular}

The measurement of group $\mathrm{C}$ forms $56.6 \%$ of the total examination. Figure 3 and Table 1 represent an enhancement of self-esteem after practical garden work for each seminar. The particularly scheduled seminar dates indicate an increased value of self-esteem in the very beginning. In the other three events, the average values heavily decrease, but display a clear difference between pre- and post-values for the third and fourth seminar. The difference $(d=1,727)$ in the third event is the only value that is significant $(\mathrm{C}=0.01 ; \mathrm{p} \leq 0,05)$.

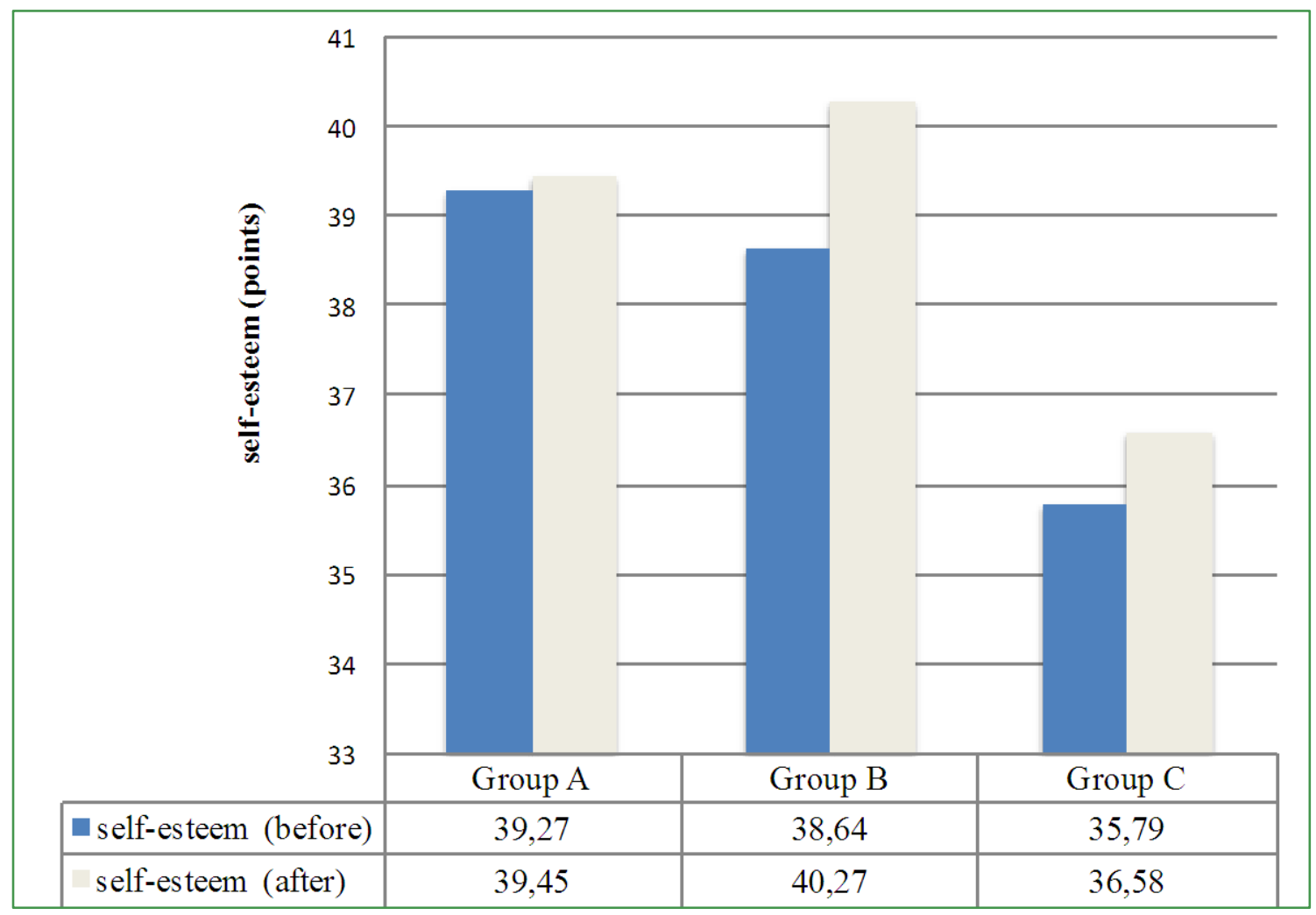

Figure 3. Comparison of self-esteem before and after practical garden work 


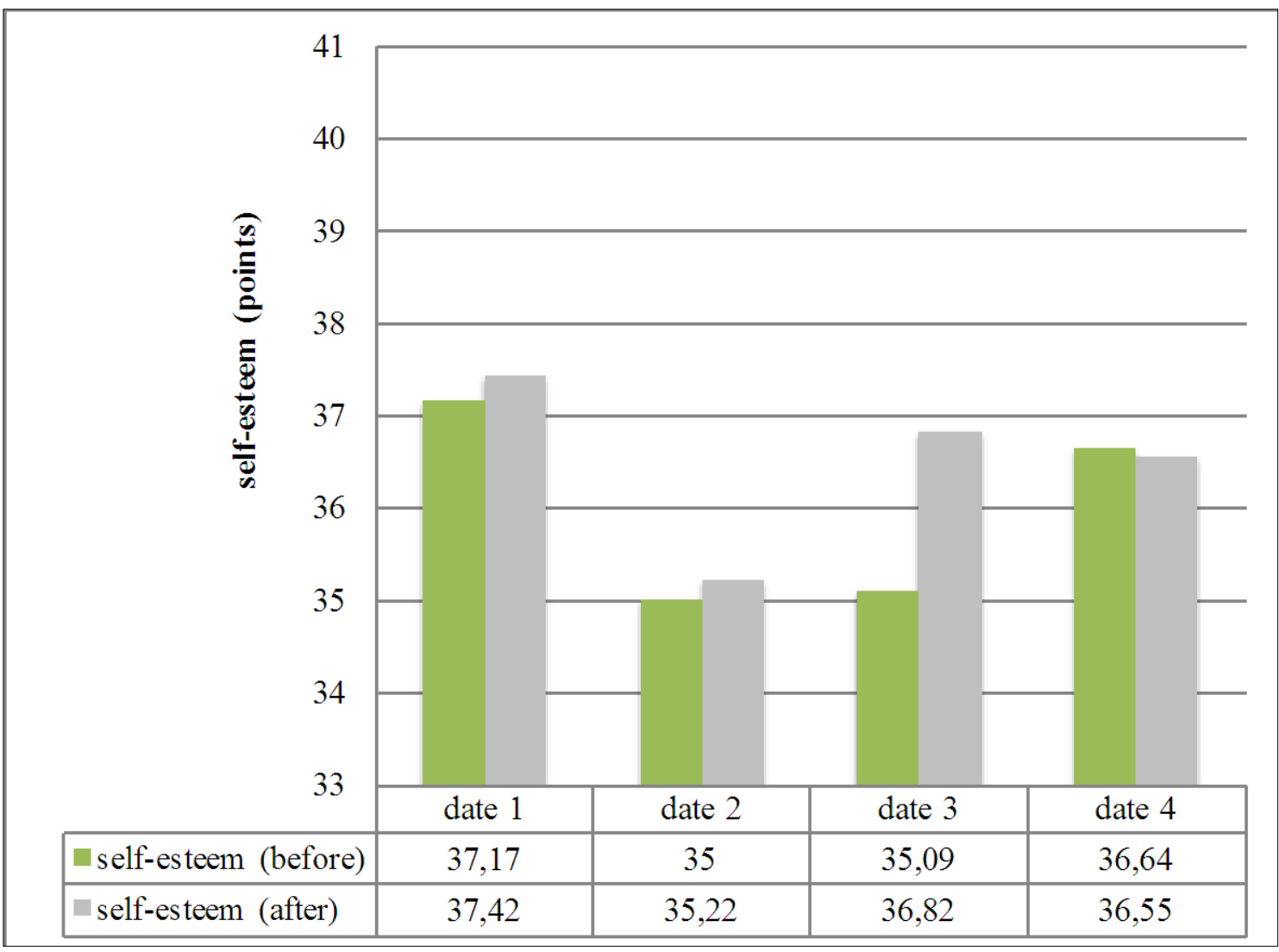

Figure 4. enhancement of self-esteem after practical garden work for each seminar for group C

Table 2. enhancement of self-esteem after practical garden work for each seminar for group C

\begin{tabular}{|c|c|c|c|c|}
\hline Group C & $\mathrm{n}$ & Corre-lation & T-Value & Significance (2-sided) \\
\hline Seminar 1 & 12 & 0,803 & $-0,477$ & 0,643 \\
Seminar 2 & 9 & 0,879 & $-0,426$ & 0,681 \\
Seminar 3 & 11 & 0,918 & $-3,099$ & 0,011 \\
Seminar 4 & 11 & 0,844 & $-1,363$ & 0,203 \\
\hline
\end{tabular}




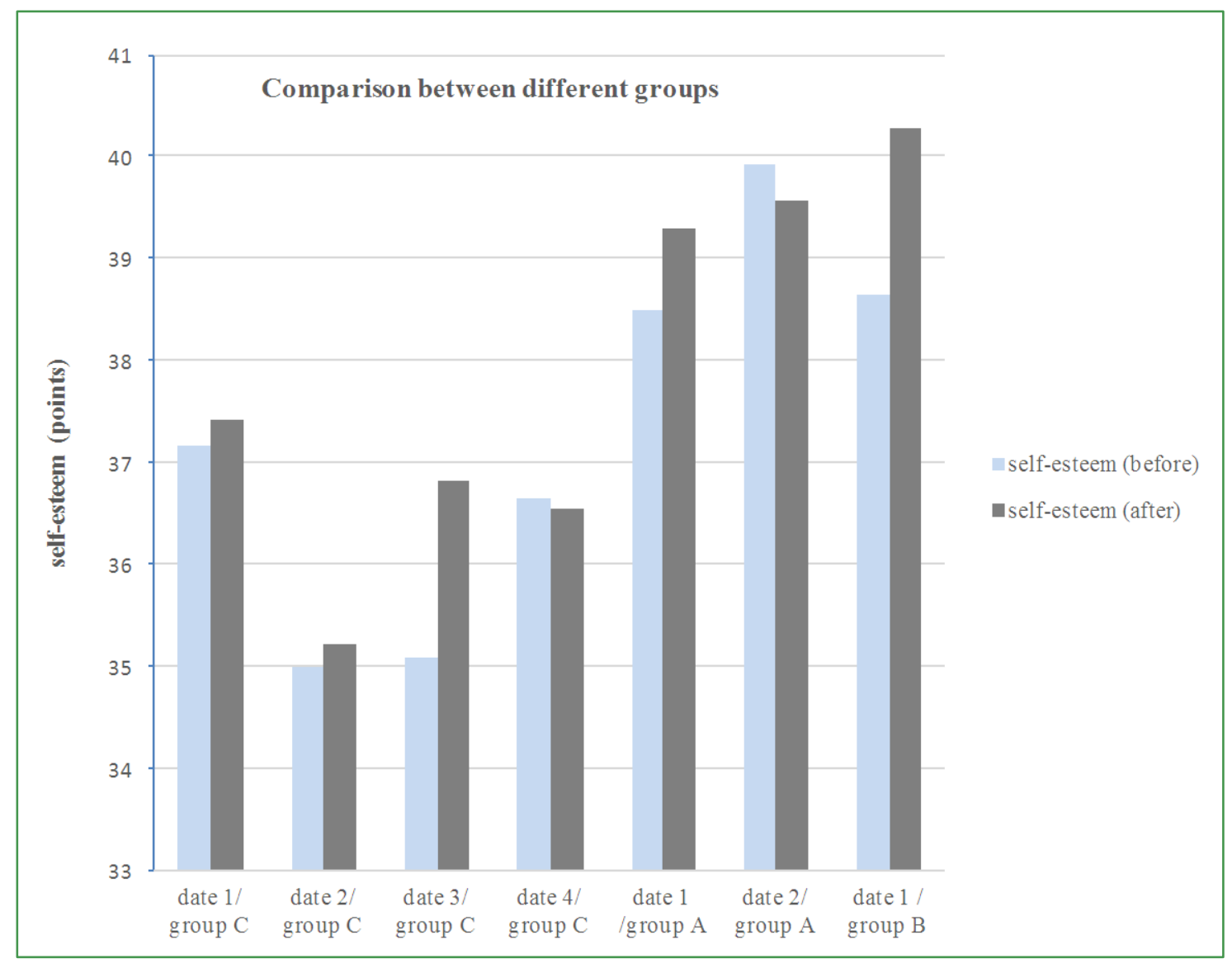

Figure 5. enhancement of self-esteem after practical garden work for group C: primary school teacher students and group A and B high school teacher students

Figure 5 shows the comparison of the results between the different groups of teacher students. Group C (on the left side of the figure) represents primary school teacher students and group A and B (on the right side of the Figure 5) represents high school teacher students.

\begin{tabular}{|c|c|c|c|c|c|}
\hline$[\mathrm{mmHg}]$ & Stud. F & Stud. G & Stud. H & $\begin{array}{c}\text { Stud. } \\
\text { I }\end{array}$ & $\begin{array}{c}\text { Stud. } \\
\text { J }\end{array}$ \\
\hline $\begin{array}{c}\text { measure- } \\
\text { ment 1 }\end{array}$ & 109 & 151 & 129 & 133 & 147 \\
\hline $\begin{array}{c}\text { measure- } \\
\text { ment 2 }\end{array}$ & 122 & 129 & 129 & 72 & 130 \\
\hline $\begin{array}{c}\text { measure- } \\
\text { ment 3 }\end{array}$ & 98 & 117 & 117 & 134 & 124 \\
\hline $\begin{array}{c}\text { measure- } \\
\text { ment 4 }\end{array}$
\end{tabular}




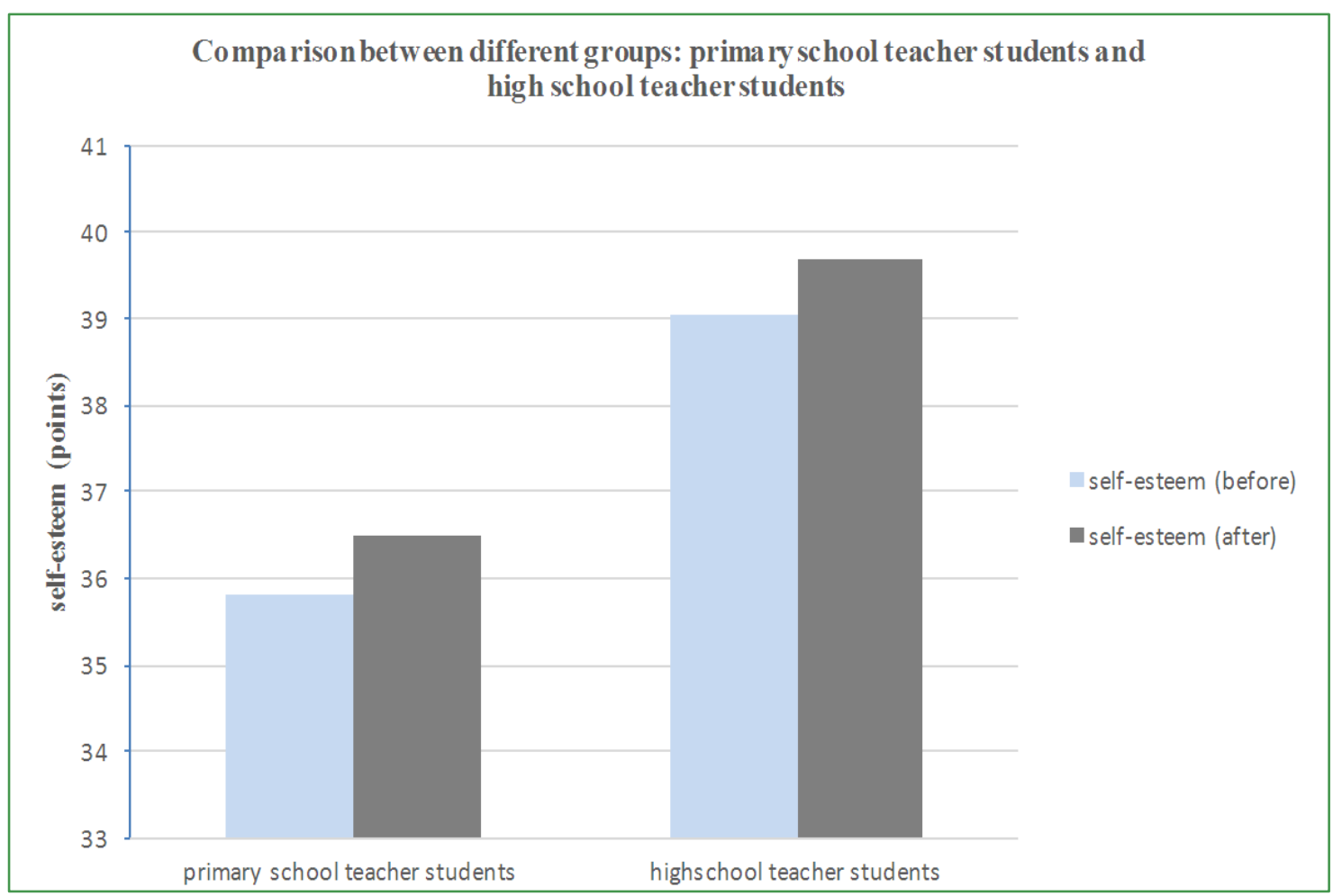

Figure 6. summary of enhancement of self-esteem after practical garden work: primary school teacher students and high school teacher students In addition, Figure 6 shows the average of the values measured.

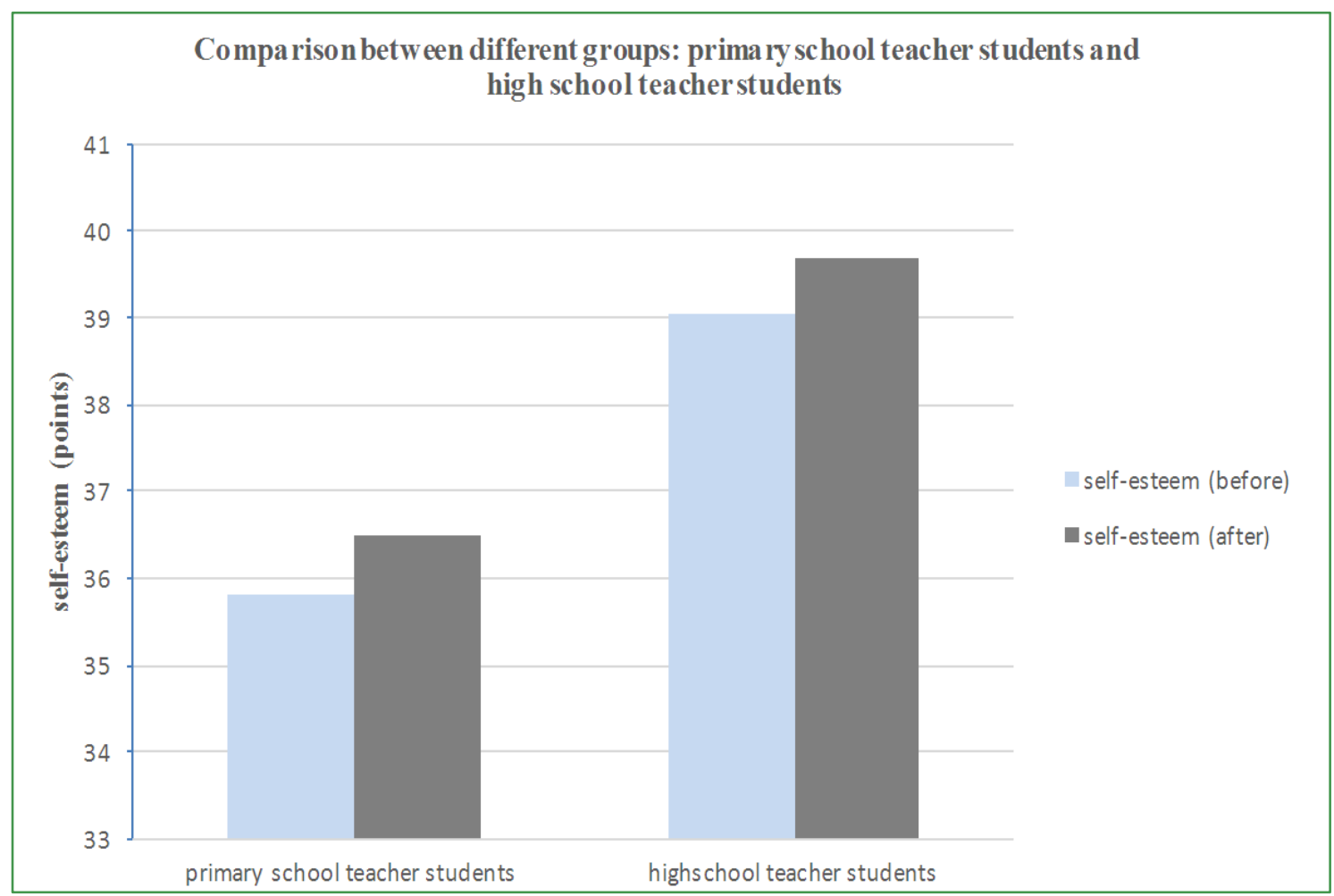

Figure 7. comparison of value enhancement 
Table 3. Systolic blood pressure while light gardening

\begin{tabular}{|c|c|c|}
\hline $\begin{array}{c}\text { group/ } \\
\text { Self-esteem }\end{array}$ & T-Value & $\begin{array}{c}\text { Significance } \\
(2 \text {-sided })\end{array}$ \\
\hline Group C: primary school teacher students & $-2,698$ & 0,01 \\
\hline Group A/B: high school teacher students & $-1,797$ & 0,082 \\
\hline
\end{tabular}

For group A/B a summary of data supporting, that the self-esteem increase from pre-value to post-value is significant $(A / B=0,082 ; p \leq 0,05)$. The value enhancement in group $C$ is even significant $(C=0,010 ; p \leq 0,01)$ (Figure 7).

\subsection{Results for Group "Blood Pressure"}

The results of the study "blood pressure" show, that the stress-induced blood pressure changes after light and heavy physical labour in the garden.

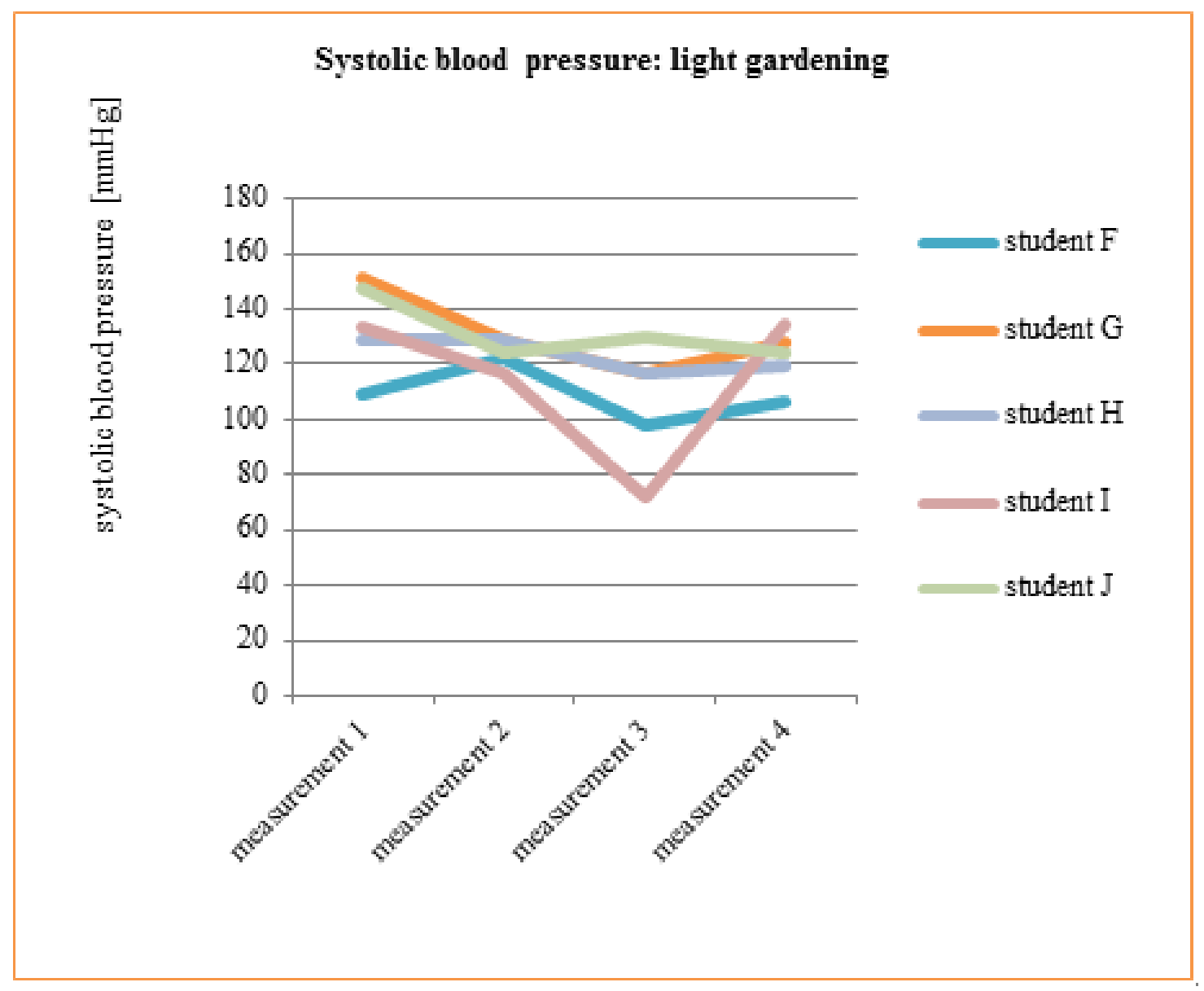

Figure 8. Values of systolic blood pressure while light gardening

The blood pressure modifies positively, especially for the light working students. The initial values of 4 out of 5 investigated people are among the final values (Table 3/11). The blood pressure of students has fallen during the investigated period. 


\section{Systolic blood pressure: heavy gardening}

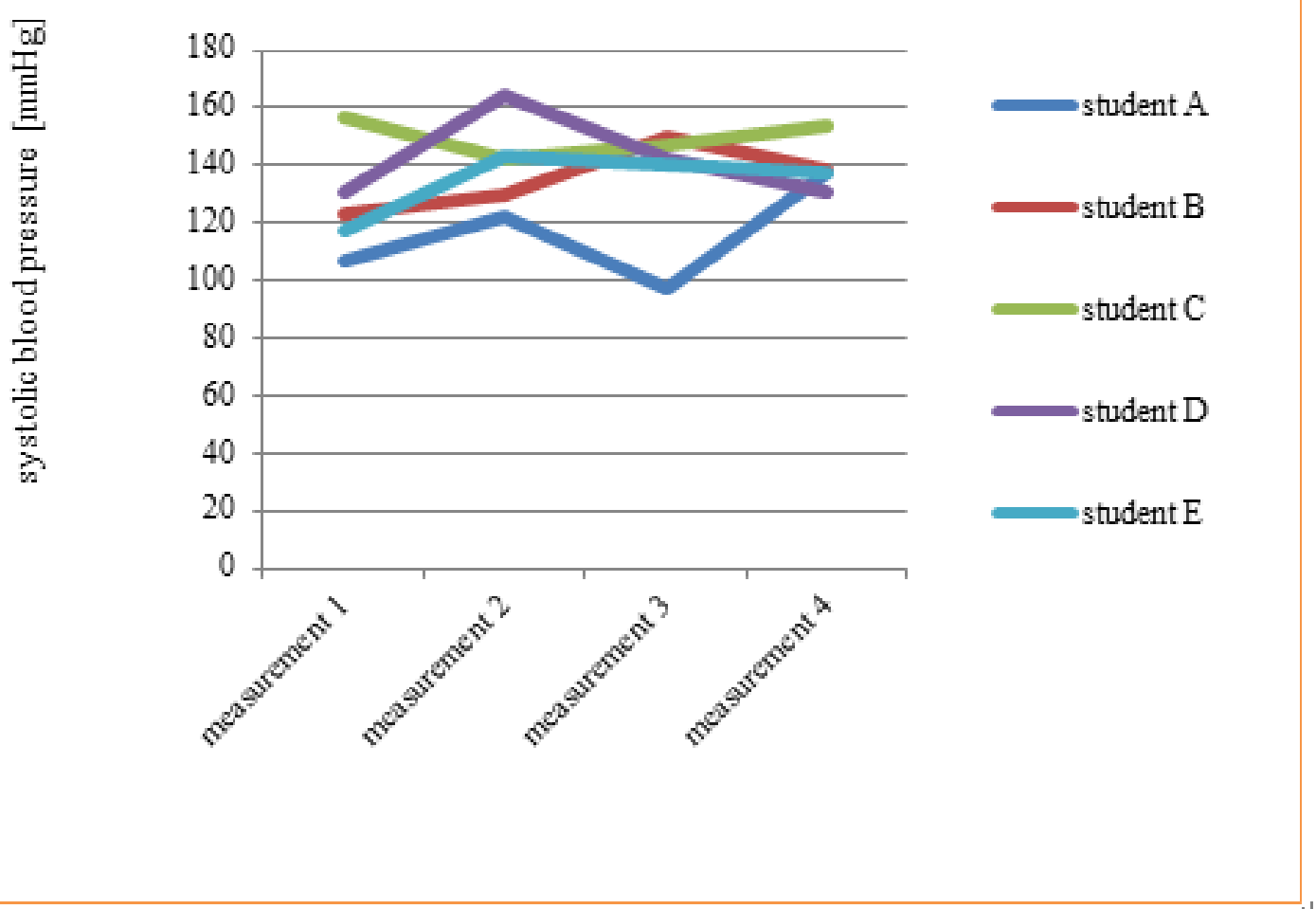

Figure 9. Systolic blood pressure while heavy gardening

Table 4. Systolic blood pressure while heavy gardening

\begin{tabular}{|c|c|c|c|c|c|}
\hline$[\mathrm{mmHg}]$ & Stud. A & Stud. B & Stud. C & Stud. D & 131 \\
\hline $\begin{array}{c}\text { measure- } \\
\text { ment 1 }\end{array}$ & 107 & 123 & 157 & 164 & 143 \\
\hline $\begin{array}{c}\text { measure- } \\
\text { ment 2 }\end{array}$ & 122 & 130 & 142 & 142 & 140 \\
\hline $\begin{array}{c}\text { measure- } \\
\text { ment 3 }\end{array}$ & 97 & 150 & 131 & 131 & 137 \\
\hline $\begin{array}{c}\text { measure- } \\
\text { ment 4 }\end{array}$ & 137 & 138 & 147 \\
\hline
\end{tabular}

The blood pressure of hard-working students also changed. The initial values of 4 out of 5 investigated people are above the final values (Figure 9/13). The blood pressure of students has risen during the investigated period.

\section{Conclusions and Outlook}

Barton/Pretty (2010) investigated the impact of nature on self-esteem and mood. They were able to prove the positive influence of nature on measured parameters depending on duration, age, intensity and location: An active nature experience of five minutes has the strongest effect on self-esteem an $\mathrm{d}$ mood. The most intense influence was found among the under 30 year old people (Barton/Pretty 2010; Bauer 2010).
In consideration of these and other findings, the presented study took following major parameters: age of under 30 , cultivated environment, short duration of gardening work in order to serve as pre-study for an extensive investigation. This investigation was planned to be set up with pupils of secondary school and was exemplarily arranged with students.

The results of self-esteem investigations indicate that practical garden work of young students increases their perceived self-esteem. Figure 3 shows a major difference between the average values of groups A, B and C. The average difference of 3.21 points not allow conclusions in view of personality traits. The parameter "subjective persuasion about one's own skills" has a decisive impact in this case (Möller et al. 2011). Another explanation for the high difference between average values of the students for 
teaching positions is the gender ratio. In groups $\mathrm{A}$ and $\mathrm{B}$ $70 \%$ of the students, i. e. participants of the study, are female. The students of group $\mathrm{C}$ have a female ratio of $93 \%$. Women proved to have a higher lack of self-esteem than men (Hahne 2011).

With regard to the average differences from pre-value to post-value, a strong increase in the course of seminars can be found (Figure 4). During the semester it is probable that motivation will decline while individually experienced stress will increase. The measurements have been taken by the end of a semester's lecture period. Preparations for exams are lead to a higher sensitivity for stress. Garden work in situations of stress increases self-esteem even more, which eventually leads a better well-being in general.

It is somewhat surprising, that there is a difference of self-esteem (Figure 6/9) between investigated primary school teacher students (group C) and high school teacher students (group A and B). Pullman and Allik (2000) compare the global self-esteem values of people of different countries. Main scores of typically "individualistic countries" are above 39 (United States and Canada 39,4 - 40,3; Australia 39,3 and other "individualistic countries" 38,5 ). "In contrast, the main global self-esteem scores estimated by RSES in collectivistic countries (e.g. Japan) tend to be notably lower (p.710)." Typical scores lie between 31,2 and 35. Thus, according to the results of presented study, primary school teacher students (group C, mean value before investigation 35,9 and after 36,5 ) could nearly be classified into the group of collectivistic countries, while high school teacher students (group A/B, main value before investigation 37,9 and after 38,7 ) could be better classified into the group of individualistic countries. This result probably shows, that teacher students groups are different audiences - with different needs. Both profit from gardening. Our research shows that primary teacher students will profit more from gardening than high school teachers students.

The results of the study "blood pressure" show, that the stress-induced blood pressure changes after light and heavy physical labour in the garden. Light gardening labour promotes a particularly positive effect on blood pressure. More detailed statistical evaluations have not been possible (and effective) in view of the small size of the sample.

The results of self-esteem and blood-pressure investigations should be transferred to practice carefully:

Biology lessons may be "dipped" in the green.

Small scale outdoor-activities have good effect on health already.

A next new study is performed in summer 2016. The aim of this new study is to investigate the effects of work in the school garden on the health of children (age 11-13, n=150). The emphasis of this new study will be on the social and emotional aspects of health, which are important components of overall health. The goal of this study is the development of a teaching unit for biology lessons in the school garden, which refers to the social-emotional context. This teaching unit has to be practical and implement/reflect curriculum requirements. Over a ten-week period, pupils of sixth grade will regularly conduct scientific and biological work at the school garden.

\section{REFERENCES}

[1] Barton, J., Pretty, J. (2010). What is the Best Dose of Nature and Green Exercise for Improving Mental Health? A Multi-Study. Environ. Sci. Technol. 44 (10). 3947-3955.

[2] Nicole Bauer (2010). Gesundheit und Erholung in Wald und Landschaft - ein Rückblick [Health and recreation in forest and landscape - a retrospective]. Schweizerische Zeitschrift fur Forstwesen. 161 (3). 120-125.

[3] Blair, D. (2009). The Child in the Garden: An Evaluative Review oft the Benefits of School Gardening. The Journal of Environmental Education. 40 (2). 15-38.

[4] Brun, J.-P. (2007). Work related stress: scientific evidence-base of risk factors, prevention and costs. http://www.who.int/occupational_health/topics/brunpres030 7.pdf

[5] Health Council of the Netherlands and Dutch Advisory Council for Research on Spatial Planning, Nature and Environment (2004). Nature and Health. The influence of nature on social, psychological and physical well-being. The Hague: Health Council of the Netherlands and RMNO, publication no. 2004/09E.

[6] Hurrelmann, K. (2010). Gesundheitssoziologie. [Health sociology] Juventa, Weinheim und München.

[7] Jäckel, L. (2010). Vielfalt intensiv erleben, genießen, wertschätzen. [Experiencing diversity intense, enjoy, appreciate] In: Artenwissen als Basis für Handlungskompetenz zur Erhaltung der Biodiversität, Band 49.

[8] Kaplan, S. (1995). The restorative benefits of Nature: Toward an integrative framework. Journal of Applied Social Psychology., (15) 169-182.

[9] Kaplan, R. \& Kaplan, S. (1989). The Experience of Nature: A Psychological Perspective. Cambridge University Press: New York.

[10] Möller, J. et.al. (2011). The Reciprocal I/E Model: An integration of models of relations between academic achievement and self-concept. American Educational Research Journal. (48) 1315-1346.

[11] Pullman, H.; Allik, J. (2000). The Rosenberg Self-Esteem Scale: its dimensionality, stability and personality correlates in Estonian. Personality and Individual Difference. (28) 701-715.

[12] Trautwein, U.; Lüdtke, U.; Köller, O.; Baumert, J. (2006). Self-esteem, academic self-concept, and achievement: Hot to leraning environment moderates the dynamics of self-concept. Journal of Personality and Social Psychology. 90 (2), Feb 2006, 334-349.

[13] Ulrich, R. S. (1984). View through a window may influence recovery from surgery. Science 224 (4647) 420-421. 
[14] WHO (2004). World Health Report. World Health Organisation, Geneva.

[15] Zerzawy, R. (1986). Blutdruckverhalten bei Normotorikern und Hypertonie Patienten während alläglicher und sportlicher Belastungen. [Pressure behavior at normotorics and hypertonic patients during every day and physical activity] In: Hochdruck und Sport: Berlin, Springer, p.35-47. 